they are now required by law, under the Safe Medical Device Act (SMDA), to report certain medical devicerelated incidents to the manufacturer and/ or the Food and Drug Administration (FDA). (Physicians offices are specifically excluded from user facility reporting.) The FDA currently is monitoring the level of reporting by hospitals and other facilities and has indicated that the number of reports coming in are significantly lower than expected. The law requires the FDA to complete a study by August 1994 to determine whether facilities have been complying with the reporting requirements. The FDA has the authority to begin imposing civil penalties of up to $\$ 25,000$ per occurrence if the study shows that facilities are not complying with the law.

The user reporting provisions of the SMDA, effective in November 1991, requires all user facilities to report incidents in which a medical device caused or contributed to the death, serious illness, or serious injury of a patient of the facility. If the facility has a question about whether an event should be reported, it may contact the FDA in writing at: Food and Drug Administration, Center for Devices and Radiological Health, Division of Product Surveillance (HFZ-340), Medical Device Reporting Inquiries, 1390 Piccard Drive, Rockville, MD 20850. FAX (301) 881-6670.

Reports must be submitted not later than ten working days after sufficient information is obtained to determine that a report is required. Deaths caused by or contributed to by medical devices must be reported to the FDA and to the device manufacturer. Serious injuries or serious illnesses caused by or contributed to by medical devices must be reported to the device manufacturer (if the manufacturer is not known, the report should be submitted to the FDA). Reporting of events caused by user error are not required by the law.

The form to be used for reporting is a preprinted test form developed by the FDA and provided to all user facilities in the FDA's 1991 Interim Guidance.

In a June 1992 amendment to the SMDA, Congress modified the definition of a reportable event. Generally, the amendments broaden the scope of events that could be considered reportable and gives the FDA the discretion to designate additional types of adverse events that would not otherwise meet the definition (e.g., concussions, temporary blindness, etc.). The FDA has not yet issued a rule reflecting these amendments, so it is unclear at this time how the changes will impact user reporting requirements. These changes will not become effective until June 1993 or until specific regulations are implemented.

The FDA has prepared and distributed the following materials to assist user facilities in complying with the reporting requirements of the SMDA:

$M$ edical D evice Reporting for U ser Facilities: Questions and Answers Based on the Tentative Final Rule,
HHS Publication FDA 92-4247, December 1991.

U ser Facility Reporting. June 1992 (a quarterly bulletin).

Copies of either document can be ordered by writing to: Office of Training and Assistance (HFZ), Food and Drug Administration, Center for Devices and Radiological Health, 5600 Fishers Lane, Rockville, MD 20857. FAX (301) 227-8067.

\section{The Department of Transportation Delays Rule on Medical Waste}

The Department of Transportation (DOT) has delayed the effective date of its final rule concerning regulated medical waste from October 1,1992, to April 1 , 1993. It is hoped that this delay will give the DOT an opportunity to consult with other federal agencies with expertise in this area and formulate a more appropriate and uniform definition of regulated medical waste that reflects the real, rather than aesthetic, health and safety risks to personnel involved in the segregation, handling, and disposal of medical waste.

The DOT's final regulations on the transport of etiologic agents, published in the December 20, 1991, Federal Register, changed the definition of "infectious substances" from "cultures and stocks of etiologic agents" to "regulated medical waste" as defined in the former Environmental Protection Agency (EPA) regulations implementing the now-expired Medical Waste Tracking Act (MWTA) demonstration program. This will increase the volume of waste that will have to be handled and paid for as regulated medical waste in most states. Even hospitals that incinerate or treat medical waste on-site will be affected unless their state definition of regulated medical waste is broader than DOT's. The regulation also includes specific requirements for labeling and packaging of waste.

The DOT's final rule marks the fifth agency that has authority over, or is actively involved in influencing, healthcare medical waste activity. The lack of coordination has led to considerable confusion in the field, often resulting in wasteful and unnecessary waste management practices.

The EPA was given the authority to regulate medical waste in the Resource Conservation and Recovery Act (RCRA) of 1976, also known as the Solid Waste Act. Rather than issue regulations, the EPA issued voluntary guidelines in the early 1980s on medical waste management practices. In 1989, EPA was mandated by Congress, under the MWTA, to conduct a two-year demonstration project of medical waste tracking and management in several states. The demonstration program used a definition of medical waste that was broader than the definition used in 
early voluntary guidelines. A final report on this program has not yet been issued.

As part of the legislation of the MWTA, the CDC's A gency For Toxic Substances and Disease Registry (ATSDR) was mandated to study the risks to public health associated with medical waste. At the conclusion of its report to Congress, the ATSDR proposed a new definition of regulated medical waste.

The CDC has published guidelines on management of medical waste since the mid-1980s, including recommended approaches for defining, handling, treating, and disposing of medical waste.

The Occupational Safety and Health Administration's final bloodborne pathogen standard of 1991 also includes a definition of medical waste, as well as requirements for handling medical waste within the healthcare facility.

Healthcare facilities are urging federal agencies to examine their current regulations or recommendations, evaluate their regulatory goals, and to work together now and in the future to develop a reasonable, coordinated policy on regulated medical waste. Position papers offering reasonable approaches to medical waste management have been developed by a number of healthcare professional associations, including the Society for Hospital Epidemiology of America (SHEA), the Association for Practitioners in Infection Control (APIC), the American Hospital Association (AHA), and the American Medical Association (AMA). Experts hope that these position papers will serve as the groundwork for a rational approach to medical waste management regulations by Congress under the new administration when it evaluates and revises RCRA.

\section{CDC Guidelines for Tuberculosis Control Debated at 0 pen Meeting} Experts in tuberculosis prevention, hospital epidemiology and infection control, biosafety, occupational safety and health, and other interested persons attending the Centers for Disease Control and Prevention's (CDC) open meeting October 22-23, 1992, advised the CDC to revise its 1990 guidelines for reducing the risk of tuberculosis transmission in healthcare facilities. Although the basic thrust of the guidelines may be appropriate, meeting participants asked for more emphasis on the education of healthcare workers and patients about risks and risk reduction, protection of human immunodeficiency virus (HIV)-infected healthcare workers, attention to transmission risks in outpatient settings, and more specific recommendations regarding ventilation, including the role of mobile HEPA-filtered units and ultraviolet irradiation. There was general recognition that definitive data were lacking on the efficacy of these alternative approaches to ventilation and that studies needed to be done. However, at the same time there was an urging for guidance from the experts even before these data become available.

Many of the participants commented that the 1990 guidelines have not yet been widely put into place. Preliminary data presented from a survey of tuberculosis surveillance and control measures in hospitals by the American Hospital Association in collaboration with the $C D C$ revealed that $217(27 \%)$ responding hospitals reported no rooms meeting the CDC criteria for AFB isolation (negative air pressure, six air exchanges/ hour, and air directly vented to outside).

Many speakers also emphasized the importance of the hierarchy of control measures-source control and administrative measures, environmental controls, and individual protective measures. In the discussion about various prevention approaches, a recurring theme was the absence of credible definitive data supporting the effectiveness, or lack thereof, of different techniques.

A highly debated topic was a recent recommendation from the CDC's National Institute for Occupational Safety and Health (NIOSH) for the use of powered air-purification respirators (PAPRs) for care of tuberculosis patients. In his closing remarks, Dr. William Roper, CDC Director, recognized the dedicated efforts of NIOSH and other CDC staff and their careful assessment of available scientific data in recommending the use of PAPRs. However, at the same time, Dr. Roper explained that he was not persuaded that there had been sufficient evaluation of the effectiveness of the current CDC recommendations regarding the role of personal respiratory protection in preventing nosocomial transmission. Dr. Roper further stated that although there may be a place for PAPRs in some particularly high-risk situations, he did not believe that there was sufficient evidence to support their routine use in the prevention of nosocomial transmission and that further evaluation of the effectiveness of current recommendations was needed before considering such a step. Dr. Roper said that the basic directions will include a strong emphasis on the hierarchy of controls, improved patient and worker education, improved worker screening and surveillance programs, additional data on the utility of all prevention and control technologies, and most importantly, full implementation of the CDC's current guidelines.

The CDC also announced that it will be working with the Occupational Safety and Health Administration to develop a joint advisory notice based on the revised CDC guidelines that can serve as a basis for national and state actions. 